\title{
Seeking Refuge: An Exploration of Unaccompanied Minors and Women from Somalia and Pakistan Experiences of Services in Bangkok, Thailand
}

\author{
Aster S. Tecle \\ Kara Byrne \\ Kimberly Schmit \\ Mary Beth Vogel-Ferguson \\ Naima Mohamed \\ Abdulkhaliq Mohamed \\ Rosemarie Hunter
}

\begin{abstract}
The number of unprotected urban refugees in Bangkok has grown over the past few years with new migrations of young women, men and families from Somalia and Pakistan. An urban environment can mean opportunity for some but for many the environment can increase vulnerability to exploitation and detention. This study aimed to explore refugees' experiences in Bangkok, assess agencies' service delivery models, and strengthen their capabilities to address service gaps. Participants were recruited using purposeful sampling and snowball. Using CBPR, focus groups discussion with Somali and Pakistani refugees $(n=63)$ and individual interviews $(n=42)$ were conducted. Agencies' staff $(n=23)$ were interviewed regarding challenges in providing services to refugees. Qualitative data analysis revealed four major themes: lack of basic need, problems with legal services, agencies revealed urgent need for shifting from emergency services towards long-term strategies given the protracted immigration status of urban refugees, and the need for a collaborative approach in service provision emerged as an urgent call. Implications to social work practice with urban refugees focusing on potentials for innovative service provision and collective agency responses are discussed.
\end{abstract}

Keywords: Refugees; urban refugees; asylum-seekers; refugee services; community-based research; partnerships

While Bangkok has always been a well-known destination for refugees and asylumseekers, something is different today. Over the past few years, Bangkok has experienced new waves of migration including women, children, and families from Somalia and Pakistan. With over 9,000 new refugees and asylum-seekers coming into the city from 1996 to 2015 the new migration phenomenon is challenging current resources and knowledge, putting into question the relevance of existing service delivery models and organizational policies (UN High Commissioner for Refugees [UNHCR], 2015b).

While an urban environment can mean opportunity for some, for many more this urban environment can increase vulnerability to being exploited, arrested, or detained (UNHCR, 2017b). Thailand is unique. The nation has not signed onto the 1951 UN Refugee Convention and does not have a legal framework in place to support asylum-seekers and

Aster Tecle, PhD, is an Assistant Professor, College of Social Work, University of Utah, Salt Lake City, Utah 84112 (UU CSW). Kara Byrne is a Research Assistant Professor, Social Research Institute, UU CSW. Kimberly Schmit is the Project Coordinator for Bridging Borders, Community Organizer and Artist, UU CSW. Mary Beth Vogel-Ferguson is a Research Associate Professor, Social Research Institute, University of Utah. Naima Mohamed is a Social Worker with the Department of Workforce Services, Salt Lake City, Utah. Abdulkhaliq Mohamed is a Partnership Manager, University Neighborhood Partners, University of Utah. Rosemarie Hunter, Associate Professor, UU CSW. 
refugees. With the emergence of the Syrian refugee crisis, and already scarce resources, crucial attention has been diverted away from Bangkok, even as the numbers of unprotected urban refugees has grown (Potter, 2014).

\section{The Context: Seeking Refuge and Finding Fear}

The United Nation's Convention Relating to the Status of Refugees, adopted in 1951, lays the foundation for international human rights relating to refugees and asylum-seekers. The Convention offers the widely accepted definition for the term "refugee" and creates the framework for states to recognize rights to protect refugees. Article 1(A)(2) of the 1951 Convention defines a refugee as a person who, "as a result of events occurring before 1 January 1951 and owing to a well-founded fear of being persecuted for reasons of race, religion, nationality, membership of a particular social group or political opinion, is outside the country of his nationality and is unable, or owing to such fear, is unwilling to avail himself of the protection of that country; or who, not having a nationality and being outside the country of his former habitual residence as a result of such events, is unable or, owing to such fear, is unwilling to return to it" (UN, 2011, p. 16). Oftentimes, when there is an influx of migrants fleeing into a country, it is impossible to process every individual for formal refugee status. In these circumstances, people may be referred to as an asylumseeker, or "someone whose request for sanctuary has yet to be processed" (UNHCR, 2017a).

Globally speaking, the UNHCR serves as the guardian for the 1951 Refugee Convention (UNHCR, 2011). This convention is an instrument for States to develop their legal framework and stemming from the UN Declaration of Human Rights, has a foundation in non-discrimination, non-penalization, and non-refoulement (UNHCR, 2011). Specifically, the Convention sets standards that give refugees access to education, work, and courts (UNHCR, 2011). Unfortunately, Thailand is not one of the states who has signed onto the 1951 Convention, leaving many asylum-seekers who have fled to this country in an extremely vulnerable situation (UNHCR, 2015b). The 145 nations that have signed onto the convention have made a commitment to significantly increase protections and overall well-being for refugees who flee to their homeland. Without signing onto the 1951 Convention and without a legal framework for handling refugees and asylum-seekers, Thailand is left with few options for handling an estimated 130,000 individuals who are asylum-seekers and refugees (UNHCR, 2016; Universal Periodic Review [UPR], 2015).

Moreover, according to UNHCR, by 2009 more than half of the world's refugees resided in cities and towns, compared to one third who live in camps. In recognition of the changes in the size and composition of the urban refugee population, as well as the protection risks facing these refugees, UNHCR released a comprehensively revised policy on refugees in urban areas in 2009. The policy has two principal objectives: (1) to ensure that cities are recognized as legitimate places for refugees to reside and exercise the rights to which they are entitled; and, (2) to maximize the protection space available to urban refugees and the humanitarian organizations that support them (UNHCR, 2009). This approach is a significant departure from the previous policy of giving primary attention to refugees in camps, and an acknowledgement that movement to urban areas can be a 
legitimate response to lack of access to livelihoods, education, and even physical and material security in some camps" (UNHCR, 2009).

While Thailand has not signed onto the Convention, the state is bound to international human rights standards, which include basic human rights along with a non-refoulement policy that dissuades a state from sending asylum-seekers back to the country from which they have fled. This has created an anomalous life experience in Thai refugee camps and urban settings. The refugee camps are an organized response to asylum-seekers; however they are deeply confining. Thailand has responded to the influx of asylum-seekers in the creation and management of nine refugee camps along the Thai-Burma (Myanmar) border. These camps house approximately 106,321 refugees from Burma (Myanmar), with a large portion of assistance coming from non-governmental organizations such as Jesuit Refugee Services (JRS) and the International Rescue Committee (IRC) (UNHCR, 2016). While the camps meet basic needs (albeit in a volatile manner), without legal rights in the country, a refugee living in a camp is restricted in their ability to come and go from the camp as they please.

Camps have been the most formalized response to asylum-seekers in Thailand, but a legal framework and response is lacking for the urban asylum-seekers and refugees arriving from nations other than Burma (Myanmar) (UNHCR, 2016; UPR, 2015). This urban population of Bangkok's refugees is changing with the emergence of Pakistani and Somali refugees in the past few year. These new populations have presented unique challenges for the agencies that serve urban refugees and are the focus of our article. Individuals seeking refuge arrive in Bangkok and initially link to services through informal networks and wordof-mouth referrals through peers. While a dense urban population makes the word-ofmouth referrals possible, this is not a sustainable or consistent mechanism for linking refugees to resources.

While struggling to obtain basic needs, individuals are simultaneously working with UNHCR to register, secure an interview, and receive determination on their migration status. While lack of a legal framework leads to a shaky foundation for these individuals seeking refuge, UNHCR continues to process these applications, perhaps in hopes that a refugee status determination will lead to increased access to resources, resettlement, or the adoption of a legal framework that will open up opportunities. With continued conflict in their countries of origin, repatriation is not an option for these individuals. At this point, however, refugee status determination simply leads to the very slim chance at resettlement. The initial interview and determination process takes time and while experience and expertise is high within UNHCR, with constrained resources towards refugee services, capacity to process asylum-seekers and refugee determination is limited. In Bangkok, individuals seeking refuge are currently waiting an average of 4 years before their refugee status claims are heard (UPR, 2015). During the course of the study, UNHCR increased the number of staff processing claims and progress was being made on the backlog of cases.

Due to the lack of national legal framework for integrating asylum-seekers and refugees, in conjunction with the lengthy wait time to begin the UNHCR determination process, asylum-seekers and refugees are vulnerable to many human rights violations. Without legal status, they are at risk for arbitrary arrest, detention, and exploitation. The 
UPR (2015), a tool used by UN states to assess human rights, lists the top five human rights concerns in Thailand as arbitrary detention, lack of basic needs (e.g., shelter, food), education, refoulement, and healthcare. Lack of legal status puts asylum-seekers at risk of being stopped and arrested anywhere in Thailand, including in their homes but the dense population in Bangkok makes the risk of detention even higher. As people travel to and from their homes, via bus, long walks, or taxi, their risks for arrest increase.

Being arrested is a traumatic experience, leading to detention and division of families. The Bangkok detention center has received negative international attention for keeping people in foul, confined conditions (Global Detention Project, 2017). Many refugees and asylum-seekers fear leaving their home with the looming threat of detention at their doorstep. As a result, the unique urban context of Bangkok, Thailand has led to an isolating and dangerous life for urban asylum-seekers and refugees.

\section{Bangkok Urban Asylum: The Journey to Limbo}

Somali and Pakistani asylum-seekers are fleeing complicated and traumatic environments. Asylum-seekers from Somalia are fleeing decades-long civil war and sexual and gender-based violence (SGBV) (Pickering, 2011). In Bangkok, the majority of the asylum-seekers from Somalia tend to be women and men in their early 20's, many who arrived in Bangkok as unaccompanied minors and single mothers. The Pakistani community in Bangkok is made up of Christians and Hammadi Muslims fleeing religious persecution. They fled as families and are living together in Bangkok.

The journey to Thailand across the Somalis and Pakistanis varies; some are smuggled, others arrive by boat, travel by bus from Malaysia, all to seek refuge in the Thai capital, Bangkok. Consistent with the interviews in this study, Pickering (2011) describes the specific terror that many women face as they travel towards asylum. The violence towards women does not end after crossing state borders but continues along the journey. Upon arriving in crowded international bus terminals in Bangkok, some seem confused on where they are, having paid for travel to a transition country as asylum-seekers and then abandoned in Bangkok (Potter, 2014). Service providers have expressed concerns over increased risk of abuse of asylum-seekers because of misinformation regarding the migration process (UNHCR, 2015b).

The lack of formal infrastructure or response has led to significant misinformation, which may exacerbate migration to cities such as Thailand, without the resources to support the influx. Families move or push their children towards a perceived better life, but that is not the case for the Somalis and Pakistanis in Bangkok (Oppedal \& Idsoe, 2015; Vervliet, Vanobbergen, Broekaert, \& Derluyn, 2014). The realities of surviving in Bangkok lies in stark contrast to their hopes of a new life (Jesuit Refugee Services, 2015). Thailand does not have a formal asylum framework and receiving official refugee status is a long process with no assurances (UNHCR, 2015b). While people wait for a chance at refugee determination and the small chance of resettlement, there is the present-day reality in limbo. In countries without effective protection measures, such as Thailand, asylumseekers are more susceptible to experience abuse from employers (Migration Policy Institute, 2015). As a result, many are unemployed or in illegal employment and risky 
circumstances. Additionally, with no documentation or work papers, Bangkok's refugee community remains vulnerable to arrest and myriad forms of exploitation and abuse (Migration Policy Institute, 2015; UNHCR, 2015a). Without a job, within weeks, Somali and Pakistani refugees find their savings depleted, languishing in a small apartment with little food, let alone hope for employment (Steele, 2014).

An asylum seeker's journey is often leaden with trauma. Studies have uncovered the trauma that women with refugee status have witnessed or experienced in their journeys away from violence, although additional research is needed to continually assess the unique needs of women in Bangkok and develop culturally relevant treatment approaches (Holt, 2013; Robertson et al., 2006; Schmidt, Kravic, \& Ehlert, 2008). Women may be survivors of rape, sexual and other forms of gender based violence (SGBV), or domestic violence and may not be initially equipped to cope with trauma (Jesuit Refugee Services, 2015).

\section{Methods}

In response to the drastic shift in the needs of asylum-seekers in Bangkok, Jesuit Refugee Services (JRS) in Thailand collaborated with faculty and students from the University of Utah, College of Social Work in the implementation of a community-based participatory research (CBPR) project. The focus was on the evaluation and improvement of the current service delivery model and examining the potential of a collective agency response to address challenges and gaps. The research team consists of staff from a local NGO, faculty, and students from the College of Social Work. Researchers conducted 42 interviews with 63 individuals representing refugee and asylum-seekers from Somalia and Pakistan The team began this project with two aims in mind:

(1) Exploring the experiences of Somalis and Pakistanis residing in Bangkok as urban refugees and/or asylum-seekers to assess and better understand formal and informal networks for accessing services, as well as gaps and challenges for obtaining services.

(2) Strengthening partners' capacity by providing trainings on case management and community practice based on local demands.

Jesuit Refugee Services and the University of Utah, College of Social Work have partnered on a variety of projects, including Bridging Borders, a community-university partnership with camp and migrant communities along the Thai/Burma (Myanmar) border since 2012. Both university and community partners expect the partnership to continue and evolve as a long-term applied research, teaching and practice collaborative with the aim of investigating and responding to refugee issues in urban settings in the Asia Pacific region.

Within a community-based participatory research (CBPR) framework, NGO partners identified the following goals for the research: a) to assess and better understand challenges accessing services; and b) to develop JRS's capacity to address service gaps. The longterm aim was to gather information that will increase case managers' understanding of diversity in the community and inform development of innovative treatment and practice aimed at working with asylum-seekers' strengths and needs. 
Working to change the pervasive narrative of refugees as needy and refugees as consumers of services to refugees as strong and co-creators of services, a community development and asset-based approach were utilized in the development, implementation, and thematic analysis of the data. According to Community Development Exchange, "A community development approach's key purpose is to build communities based on justice, equality and mutual respect. Community development involves changing the relationships between ordinary people and people in positions of power, so that everyone can take part in the issues that affect their lives. It starts from the principle that within any community there is a wealth of knowledge and experience which, if used in creative ways, can be channeled into collective action to achieve the communities' desired goals" (2008).

Community Based Participatory Research (CBPR) is another way of collaborating with communities to explore and better understand social phenomena communities are experiencing. CBPR is a process of learning and knowing based on communities' own terms (Minkler \& Wallerson, 2003; Strand, 2000). Communities identify, describe, assess and plan ways of addressing social issues of concern with research experts engaging as partners or collaborators (Anderson, 2006; Strand, 2000). One of the unique characteristics of CBPR as a methodology and method is that CBPR is based on the premise that communities' ways of knowing are central and equally legitimate as any other centered knowledge, in research and that CBPR is action oriented towards social transformation (Strand, 2000). Communities take charge of their own affairs in terms of design, implementation and follow-up, which ensures sustainability, together with mutual and equally shared partnerships with external partners. The goal of such an interpretive research was to better understand a phenomena for the researchers and those impacted by the social phenomenon so that both of them can explore alternatives or other possibilities (Yanow, 2000). Social work practice being inherently pedagogical (Freire, 1990), using CBPR and field observation to explore immigrants experiences in Bangkok was central as a colearning process and building relationships during the study period. Utilizing these paradigms, the research team made up of lead individuals from JRS and the CSW codeveloped the research topics and questions, research methods, and identified key community, agency, and community based organization stakeholders to be interviewed. The following sections include the interview, study participants and emerging themes from the study followed by discussion and future plans.

\section{The Interviews}

In order to develop a comprehensive service delivery and advocacy response supporting urban refugees and asylum-seekers from Somalia and Pakistan, interview guides gathered information on: the experiences in accessing services and the challenges of newly arriving communities to better understand existing gaps in services and inform practice.

As summarized in Table 1, 42 interviews were conducted with 23 NGOs and CBO's staff who served and advocated for the refugee communities, and with 63 refugees and asylum-seekers from Somalia and Pakistan. The research team included faculty (4), students (2) and community partners (2) who conducted the interviews. Through a purposeful sampling technique, service providing agencies identified refugees and asylum- 
seekers and recruited those who were willing to participate in the study. A snowball method also occurred, sometimes with interviewees mentioning another person to interview and sometimes the translator. All of the interviews happened in the interviewees' apartments or a neighbor's apartment. Conversations with staff from JRS, other agencies and community based organizations happened at their respective places of work. Participants from agencies and CBOs were mainly staff selected randomly.

Table 1. Number of Participants and Interviews

\begin{tabular}{l|c:c}
\hline \multicolumn{1}{c}{ Participants } & $\begin{array}{c}\text { \# of } \\
\text { interviews }\end{array}$ & $\begin{array}{c}\text { \# of people } \\
\text { interviewed }\end{array}$ \\
\hline Agency Staff & 9 & 17 \\
Community Based Organizations & 4 & 6 \\
Somali Community Members & 21 & $23\left(16 \circ, 7 \jmath^{\top}\right)$ \\
Pakistani Community Members & 9 & $17\left(13 \circ, 40 \begin{array}{c}\top \\
\text { Total }\end{array}\right.$ \\
\hline Total & $\mathbf{4 2}$ & $\mathbf{6 3}$ \\
\hline
\end{tabular}

Jesuit Resettlement Services (JRS) provided Somali and Pakistani translators for the relevant interviews. The translators received training by College of Social Work (CSW) researcher team. The research team also included members with refugee and/or asylum seeking backgrounds now residing in the United States. For example, one researcher, a US citizen originally resettled from Somalia and was extremely valuable to the team in developing trust with the Somali community in Bangkok, as well as providing other team members with cultural context. It is important to mention that the interviews were conducted the week following a raid in the communities where some of the interviews took place. JRS and interviewees reported that between 40-65 asylum seekers and refugees were arrested including 25 children.

The partnership relied heavily on community-based interpreters of refugee background, not only to translate interviews but also serving as guides in the community, community liaisons, and connecting with potential participants. The research team came to develop important professional relationships with the translators, filled with trust and deep respect. The interviews took place in neighborhoods across Bangkok where the Somalis and Pakistanis were living, and at agencies' offices. An IRB application was approved by the University of Utah. It is important to note that the research team made explicit decision not to ask interviewees about the reasons for immigrating to Bangkok from Somalia and Pakistan, nor about their migration stories. This was to avoid re-traumatizing the individual, as well as to move away from the dominant, and disempowering, approaches to refugee narrative that focus mostly on trauma stories. However, participants shared their stories, which could be due to power differentials, or the possibility that comes with telling one's story, or simply the familiarity that comes with sharing one's life story with interviewers. The research team embraced the stories as potentially therapeutic and a natural opportunity of listening to support healing. Collected information was transcribed, reread and discussed by team members. Together with partners' contributions, shared identification of major themes revealed recurring events and experiences participants reiterated during the interview. The results section details what emerged from the conversations. 


\section{Results}

With the exception of one female, Somali interviewee, individuals reported leaving Somalia when they were between the ages of 13 and 16, with age 15 as the most common. $68 \%$ interviewed had been in Bangkok since 2014 (2 years at the time of the research), $21 \%$ after 2014 (less than 2 years), and $11 \%$ before 2014 (more than 2 years). The next section presents three major themes from the findings of this study, (1) Services and support in Bangkok, (2) Legal services and (3) Shifting towards a collective response. Examples of each theme can be found in Table 2.

\section{Themes}

Table 2. Major Themes

\begin{tabular}{l|l}
\hline \multicolumn{1}{c}{ Themes } & \multicolumn{1}{c}{ Examples } \\
\hline Basic needs and referrals & "I went Agency 1, but they send me back to Agency 2. When \\
I go to Agency 2 then they send me back again to Agency 1." \\
Legal services & "Agencies collaborate but refugees don't know" \\
Shifting to a collective response & "Scattered resource locations won't work" \\
\hline
\end{tabular}

\section{Basic Needs and Referrals}

While agencies who provide services to urban refugees provide information about their services, study participants shared that there is a lack of information regarding what services exist for asylum-seekers, how to access these services, and an understanding of how the systems work in Bangkok. UNHCR provides a booklet with information about all the NGOS and their services to individuals who visit their offices. Nevertheless, individuals who participated in the interviews indicated that the primary way to contact service providing agencies (Community-Based Organizations [CBOs], Faith-Based Institutions [FBIs] and Non-Governmental Organizations [NGOs] is through word of mouth from their respective communities, informal connections with other communities, and referral to these agencies. Many study participants shared a similar story of being lost and isolated when arriving in Bangkok, often not knowing where they were or who and how to connect to resources in the community. Resources are scattered around the city and transportation into the heart of the city felt like navigating a maze. A female, 17 years old participant recounts his arrival to Bangkok:

So the thing is, when I first arrived here, I took a cab to drive me to the town but I had no clue where to go or if there were some Somali people around this area, so I was taking the cab and I've been in the cab for a long time, but when I was passing here I have seen 2 Somali passing by and I recognized their face and their color and I told the cab driver to just stop and leave me. I get off the taxi and I talk to the guys and they ask me, 'Are you Somali too?' I said, 'Yes.' Then the 2 Somali men took me to where 3 Somali men were living in a room and they told them about my situation that I just got off the taxi and I don't know any person here so they told them that I should at least stay with them for a while until I know places. 
Representatives of participating agencies indicated that the process to gaining access to services ideally starts with the UNHCR. This process includes registration with the UNHCR to gain refugee status in Thailand based on the credibility of each case. When UNHCR legally validates asylum-seekers' cases for refugee status, they get a card from UNHCR implying that they have status as a refugee but not legal status in Thailand. Additionally, not all asylum-seekers obtain the UNHCR card because they do not meet the criteria or because of the prolonged waiting period to meet with UNHCR since arrival in Bangkok.

According to participants, the UNHCR's card facilitates access to services, but does not protect them from Thai immigration officers' random detentions. The acknowledgement of status from UNHCR allows asylum-seekers to follow-up on referrals to services provided by CBOs, FBIs and NGOs in Bangkok. The types of services CBOs, FBIs, and NGOs provide are primarily basic human needs including food, healthcare, education, and housing. The services vary in terms of quality and permanency. Asylumseekers noted that they get confused regarding who is providing what type of services and for how long. The agencies keep on referring them from one agency to another. They may also roam around based on word-of-mouth and lose hope and trust in the agencies. Given the lack of a national legal framework, the access to referrals can be random and happenstance. Individuals resettle themselves around the city and find UNHCR, Asylum Access Thailand (AAT), or other international NGOs rather haphazardly.

When I was first registering at the UNHCR, I've been told that there are some organizations that help the people and later on I also ask the Somali people to show me those places that I can ask help from.

In addition to the location of organizations being scattered around the city, the provision of services was assorted. For example, some CBOs, FBIs and NGOs focus on provision of food, while others provide health care services, education, or shelter. Some agencies provide two or more types of services. FBIs, for instance, focus on providing food, more often than not based on those who register with them and attend church services and activities. Other well-established churches provide services to all asylum-seekers, asylees and refugees in Bangkok regardless of their membership in that specific church. For example, Calvary church conducts home visits to protect recipients from the risk of random detention in the streets. However, as time goes by and asylum-seekers do not hear from the UNHCR, they start losing hope. As one female participant shared,

We are here for long time and we still don't know really that we have the results, if they are going to reject us, if they are going to refuse us, or what they are going to do, we don't know. Every day is a different day and we don't know each day what is going to be happening.

While there are several NGOs providing a variety of services, in our interviews, we found that there are three well-known agencies that seem to be focal points for providing for meeting basic human needs: JRS, Bangkok Refugee Center, and Yateem TV. JRS is an international Catholic non-profit organization established to serve and advocate for refugees and internally displaced populations worldwide. The organization has regional offices around the world, including South Asia. In Thailand, JRS typically provides 
psychosocial counseling, financial assistance, and material resources for asylum-seekers. JRS provides basic services to newly arriving asylum-seekers for six months based on AAT referrals for psychosocial counseling and will then refer out for medical services. According to one of the representatives, the support is short-term due to lack of funding. In addition to short-term monetary support, JRS also provides training for parents and children, including English and Thai language courses, mainly to train people in skills that would serve them locally and when resettled in a third country. JRS also refers asylumseekers and refugees to the Bangkok Refugee Center (BRC), an arm of UNHCR, for services they do not provide.

Bangkok Refugee Center (BRC) is the branch of UNHCR that provides on-the-ground assistance, including medical screening for newly arriving asylum-seekers. The BRC is located in a residential area of Bangkok and receives walk-ins, unlike the UNHCR office, which is closed to the public, requires an appointment, and includes extensive security clearance for entry. BRC, on the hand, is a setting where individuals can attend classes, receive assessments for other services, referrals to other agencies, and additional social services. BRC has a bridge school at the center where refugees' children learn Thai for six months to help them transfer to Thai public schools. This center also provides health services even though, according to representatives of the agencies, access to medical treatment is not guaranteed for asylum-seekers and refugees. The BRC and JRS are two agencies that provide resources and services to the urban asylum-seekers. One agency, Yateem TV, is unique, in that they are focused on providing actual housing for the urban asylum-seekers in addition to a variety of services.

Yateem TV is a Bangkok NGO led and run by a local Muslim addressed as Sheikh. The agency provides varied services not only to asylum-seekers but also to the poor and low income in Bangkok. Local Thai businessmen, leaders of the Muslim community appointed by the King, and the Thai Muslim Center support Yateem TV. At the center, there are faith-based services, large spaces for gathering, and space whereby volunteers cook food for anyone who cannot afford to feed him or herself in the city. Participants admitted that Yateem TV is a welcoming space for urban refugees and asylum seekers in Bangkok. Furthermore, the agency gives adults financial incentives to learn English and pays for school transportation for youth. Given the dispersed population of asylum-seekers and resources, access to transportation is of vital importance. Yateem TV is well-known for providing asylum-seekers and refugees with free of charge apartments and/or paying for their rent. According to Yateem TV representatives, bringing together asylum-seekers and refugees across various communities has been key to the communities' ability to support each other. Still, as important and accessible as this organization is for the Somali community, during our interviews we found some young women who did not know of Yateem and described a sense of fear about going outside of their apartment buildings, as there was no place for a Somali woman to hide from police and avoid the risk of detention. As a 16 years old female Somali participant shared,

I've been staying in the room without going to the UNHCR and registering myself in the UNHCR 14 days because I was afraid if I go out I will be arrested. But you know, I couldn't just keep myself in the room and I went out one day and I registered in the UNHCR but after a while, I, as I went to the BCP office and 
registered in that office as a minor an unaccompanied minor, I went to back to my home and when I arrived at my home, I entered the room, a knock at the door. I didn't know them, they just entered the room and we were captured and we have been taken to the IDC, to the prison.

Asylum-seekers who migrated from Africa in particular, their skin color exposes them to racist attitudes they have to endure every day of their lives, and that would also make them easy targets of immigration officers who roam around their neighborhoods. Moreover, as service users, they have to take public transportation or a taxi to visit these agencies for services. The drive can take two hours to get to the agencies depending on the traffic. The financial resources they need to take a taxi or public transportation, and the long hours drive to go back and forth to visit the agencies, not to mention during emergency, puts them at great risk of being questioned and detained. Yet they have no other choice but to take the risk. When meeting with a family of four from Pakistan, the father said,

There is one church.... There is one Indian lady and she got care from the church. They are providing food for the people. Nobody help for the rent, only JRS they do help. JRS also have limited sources, they will help you in emergency cases. ... I have $a$ son and he is not normal and he is not taking a normal food as well. What I have to give to him is always I have to spend money. He have a very heavy medicine and if I don't choose the milk, if I give him the medicine without milk, then he have starting to have motions, and we have to buy the pampers for him. There is not any organization that is helping to us that we can live here easily. Especially, the people like me, who have children for special needs or have some medical issues, it is really difficult for these type of people to stay here.

In addition to security issues, nothing seems to be enough and/or there is no one to fill in the gaps when lack of basic needs is the main issue.

\section{Legal Services}

UNHCR and Asylum Access Thailand (AAT) are the primary agencies that provide legal services for urban refugees and asylum-seekers in Bangkok. IDC issues. In addition to processing status applications, UNHCR works with the government on system level issues and with the local Thai police. Their role is to educate local police about what the UNHCR card means and provide a context for migration and the people seeking refuge in Bangkok. In this way, UNHCR strives to assist the police with considering the priorities around crime in the city and to deter them from arresting people whose only violation is their status. UNHCR staff will go out into the community to meet with police and military groups to provide education about refugees and asylum-seekers and to discuss bailout programs for individuals who have been arrested and are in detention.

In addition to providing legal services, AAT also works with refugees and asylumseekers to assist them "to organize and assert their rights." AAT works with identified community leaders and supports them in developing the capacity of the community to develop advocacy and action efforts. For example, in Bangkok, AAT is active in supporting 
Somali and Pakistani communities with forming and running democratic collective action groups. These groups are initiated and run by the urban refugees. Another example is the community paralegal program. AAT has also developed formal public/private partnerships, such as partnering a private Law Firm with the International Refugee Assistance Project (IRAP). Additionally they have been successful in engaging a corporate law firm with providing pro bono legal aid and developing legal briefs for advocacy and policy work. These public/private partnerships have also supported the work of UNHCR. By working with community leaders, AAT learned that these direct connections to the community are the most beneficial way to get and share information and to support organizing efforts, as well as to get legal and human rights assistance directly to urban refugees.

However, the fears of one's apartment been raided, picked up from the streets and detained remains to be threatening refugees who hesitate between taking the risks or not even for the sake of feeding their children and/or going to clinics. One female Somali participant describes her sense of living in constant fear.

I'm always afraid if I am going out or if I am staying inside, if I accompany my daughter to the school, if I try to pick up her from the school, I always, I'm always afraid about it.

As people travel to and from their homes, via bus, long walks, or taxi, their risks for arrest increase. As a young 16 years old Somali male shared,

When I came to Bangkok, I didn't have any information about it. I didn't know the name of the city. I didn't even know there were Somalis in Bangkok. But when I arrived here and I met Somali people they told me that the people are arrested for being illegal immigrants here. And they frightened me. I've been staying in the room without going to the UNHCR and registering myself in the UNHCR 14 days because I was afraid if I go out I will be arrested. But you know, I couldn't just keep myself in the room and I went out one day and I registered in the UNHCR but after a while, I, as I went to the BCP office and registered in that office as a minor an unaccompanied minor, I went to back to my home and when I arrived at my home, I entered the room, a knock at the door. I didn't know them, they just entered the room and we were captured and we have been taken to the IDC [Immigration Detention Center], to the prison.

Despite the efforts of legal experts, the lack of information about legal services, lack of transportation and fears of leaving their homes have left urban refugees in Bangkok isolated and insecure. Six of the Somali interviewees (three female and three male) had been in IDC themselves and $50 \%$ of those report having been beaten or tortured during their time there. The amount of time spent in IDC varied greatly-between 12 days and 2 years. Conditions were described as "awful and difficult". Concerns within IDC include: cramped quarters (200 men in one room), the spread of disease (i.e. TB), lack of water, children being born inside and "being impossible to provide for", corruption and discrimination amongst IDC staff, unpredictable and inequitable system for getting out and bailout being open, etc. They also discussed how once someone is in IDC it is very hard to build their resources again. 
Usually when they are arrested, all the work that we have done build them up and helping them achieve goals, sustainable, and mental health, and well-being, all of that just falls apart, so it is a constant challenge for us to help people in this environment where they are so subject to these risks of arrest....everything falls apart.

As the agencies indicated, urban refugees' illegal status leaves them vulnerable to their employers and residential property owners. Hence, the need for coordinated and geographically accessible legal service sites essential for refugees.

\section{Shifting to a Collective Response}

Overall, while both service providers and asylum-seekers claim availability of varied services, the services are not enough in terms of quality, longevity, and types of services. For instance, according to a representative of an NGO, "UNHCR resources are draining due to the global focus on the Middle East, mainly the Syrians." Some agency representatives indicate that many of the NGOs do not have enough resources to provide services until asylum-seekers are resettled in a third country because of financial, human, and material resources. An NGO male staff member who has been working in the areas of case management with urban refugees explains the situation.

We are struggling in all the social sectors. There are not enough resources, basic needs are not met,..nowhere for single people to live, and there are limited health services.

While the agencies are dispersed around Bangkok and services are varied, there has been a growing trend to collaborate and work towards a collective response to the influx of urban asylum-seekers and refugees. Each agency may also be providing two or more types of services, which has led to the need for networking and coordination of services to maximize resources and have greater impact on the individuals and families they serve. For example, the Tzu Chi clinic (an Indian community-based clinic), has organized with BRC, UNHCR and Muslim communities to support Christian churches in emergency times. This community-based clinic provides free services including medical tests, $\mathrm{x}$-rays, dental services, and medications at no cost. The clinic itself is a collective of pro-bono doctors and nurses providing free services for those seeking refuge in Bangkok. At the time, they reported serving 700 to 800 patients every month. Study participants repeatedly acknowledged the importance of these agencies for urban refugees in Bangkok. A 20-yearold Somali female stated it this way.

The country doesn't recognize the refugees and there's no one who helps the refugees so deep down in my heart, I believe that it's only the UNHCR, BRC, JRS and BCP that can help the refugees.

There are a number of advocacy collectives that come together to assess and respond to the growing needs of refugees and asylum-seekers in Bangkok. The Core Urban Refugee Network meeting is an example of one of these collaborative efforts. They meet once every two months among the NGOs serving these communities. The Bangkok Asylum Seeker and Refugee Assistance Network (BASRAN) is another form of network holding open 
meetings whereby UNHCR and the American Embassy staff can attend. The BASRAN group breaks up into interest groups (i.e., health, education, etc.) so that each one of the sub-groups can concentrate on their expertise.

During our interviews with agency representatives, we found strong desire across NGOs, Community Based Organizations (CBOs), Faith Based Institutions (FBIs) and UNHCR to increase their networking and coordination of services. Indeed, it was the desire on the part of JRS for an increase in understanding of the community networks, both formal and informal, that sparked this research. As the spectrum of organizations who support these communities are increasingly stretched with higher numbers and shrinking resources, they are searching for a collective response that can maximize the resources. University of Utah, CSW and JRS partners are using the information gained from this study to inform a process that will enable interested partners to shift from an emergency service provision model to sustainable, and long-term solutions. The partnership aims to strengthen JRS and University of Utah partnership for further research that will inform larger practice and advocacy frameworks related to refugee and immigrant services to address misperceptions, misinformation, and acts of exploitation of migrant communities, and formulate a plan for improving services through a collective response.

\section{Discussion}

Service-providing agencies for urban asylum-seekers and refugees in Bangkok are doing their best with available resources. Efforts to move beyond conventional approaches to service users and working independently despite the overlaps of the service demands has led agencies to engaging in dialogues around collaborations. Such collaborative efforts would not only maximize agencies' resources but also minimize service users' efforts to seek support.

Considerations of advocacy and systems level changes, as well as JRS' initiative of shifting their approach from an emergency to long-term and sustainable interventions, and expanding the initiative to other agencies, are underway. Such efforts would also address the main challenges asylum-seekers are facing including the lack of sufficient resources and information, length of time for interviews, and risk of arrest and detention. Investing in sustainable skills is strategic and will have long term effects that would also be reflected when asylees and refugees get resettled in a third country.

Asylum-seekers are often trapped and deserted in the poor sides of the city, with poor infrastructure and environmentally unhealthy neighborhoods. For those who migrated from Africa in particular, their skin color exposes them to racist attitudes they have to endure every day of their lives, and that would also make them easy targets to immigration officers who roam around their neighborhoods or the agencies they visit for services. There is a felt need for a national framework that would reconsider the basic rights of asylum-seekers, their immigration status, and access to basic social services including employment rights and security from random detentions so that they can sustain their life until decisions are made regarding their resettlement process. 


\section{Study Limitations}

This study could have been stronger if study participants were identified through a random selection based on neighborhoods where asylum-seekers and urban refugees reside. Having research team members who could speak languages spoken by all study participants would also have strengthened the discussions. Moreover, since the translators were also urban refugees and/or asylum-seekers, safety concerns limited their mobility to interview sites. The team shared some incentives with study participants. However, the basic needs were beyond the incentives and created discomfort and uneasiness among team members. Bringing all study participants - refugees, asylum-seekers and staff from agencies and $\mathrm{CBOs}$ - to focus group discussions would have yielded powerful conversations around their basic needs, legal services, and the future.

\section{Remarks for the future}

The findings from this research are not meant to be conclusive of either all Somali and Pakistani urban refugees in Bangkok or the agencies and community-based organizations working with them. More so, it is meant to provide a snapshot, highlighting the voices of those interviewed. This study was a starting point to explore the experiences of urban refugees and asylum-seekers in countries whereby legalized protection does not exist. The findings have serious implications for social work practice with urban refugees and asylum-seekers in such contexts including cultural sensitivity during practice with diverse communities, having information regarding sources of resources easily available and in different languages, having systems in place rather than responding to emergency calls from newly arriving refugees and asylum seekers, and coming up with innovative approaches to service with communities in danger such as living and/or providing services within communities' apartment buildings and neighborhoods.

Overall, while service providing agencies' and CBOs' initiatives are hopeful there is a prerequisite for a political commitment and will of the agencies to ensure that a national framework is in place, and collaborative approaches to protect and serve asylum-seekers are strengthened and translated into action. Exploring formal and informal networks is essential to help asylum-seekers realize their potential to support themselves.

The research team is aware of the power differentials involved in outside researchers coming into communities for short periods and believe the role of the community translators was paramount in the success of the conversations. Our sincerest thanks is extended to them, both for the wisdom they offered as well as the risks that they took in creating access to their communities.

Finally, sharing and disseminating what partners have learned from this study at different venues and through varied means (publications, conferences, community events, etc.) is essential. Getting informed and learning from other models of working with asylumseekers including University of Utah model of serving refugees in their residential areas, including inside apartment complexes, to meet unsecured asylum-seekers and refugees where they feel comfortable and safe is critical. An important aspect of the CBPR framework is the value of research findings as community owned. There is a commitment 
to provide the findings directly to those who participated in the study and those most affected by the issues.

\section{References}

Anderson, D. K. (2006). Mucking through the swamp: Changing the pedagogy of a social welfare policy course. Journal of Teaching in Social Work, 26(1/2), 1-17. doi: https://doi.org/10.1300/J067v26n01_01

Friere, P. (1990). A critical understanding of social work. Journal of Progressive Human Servies, 1(1), 3-9. doi: https://doi.org/10.1300/J059v01n01_02

Global Detention Project. (2017). Thailand. Retrieved from https://www.globaldetentionproject.org/countries/asia-pacific/thailand

Holt, M. (2013). Violence against women in the context of war: Experiences of Shi'I women and Palestinian refugee women in Lebanon. Violence Against Women, 19(3), 316-337. doi: https://doi.org/10.1177/1077801213485550

Jesuit Refugee Services. (2015). Psychosocial accompaniment for women and girls in Bangkok. Retrieved from http://www.jrsap.org/campaign_detail?PTN=PROMO20130613023023\&TN=PROJECT-20150614105706

Migration Policy Institute. (2015). The Asia-Pacific and women's labour migration [Audio]. Retrieved from http://www.migrationpolicy.org/multimedia/asia-pacificand-womens-labour-migration

Minkler, M., \& Wallerson, N. (2003). Community-based research for health. San Francisco: Jossey Bass.

Oppedal, B., \& Idsoe, T. (2015). The role of social support in the acculturation and mental health of unaccompanied minor asylum-seekers. Scandinavian Journal of Psychology, 56, 203-211. doi: https://doi.org/10.1111/sjop.12194

Pickering, S. (2011). Women, borders, and violence: Current issues in asylum, forced migration, and trafficking. New York: Springer. doi: https://doi.org/10.1007/978-1$\underline{4419-0271-9}$

Potter, M. (2014, November 14). Thailand refugees: Please tell the world we exist. Toronto Star. Retrieved from http://www.thestar.com/news/world/2014/11/14/for_thailands_migrants_a_life_in_li $\underline{\text { mbo.html }}$

Robertson, C., Halcon, L., Savik, K., Johnson, D., Spring, M., Butcher, J.,...Jaranson, J. (2006). Somali and Oromo refugee women: Trauma and associated factors. Journal of Advanced Nursing, 56(6), 577-587. doi: https://doi.org/10.1111/j.13652648.2006.04057.x

Schmidt, M., Kravic, N., \& Ehlert, U. (2008). Adjustment to trauma exposure in refugee, displaced, and non-displaced Bosnian women. Archives of Women's Mental Health, 11(4), 269-276. doi: https://doi.org/10.1007/s00737-008-0018-5 
Steele, S. (2014, May 5). Pakistan Catholics flee to seek refuge in Bangkok. UCAnews.com. Retrieved from http://www.ucanews.com/news/pakistan-catholicsflee-to-seek-refuge-in-bangkok/70855

Strand, K. J. (2000). Community-based research as pedagogy. Michigan Journal of Community Service Learning, 7(2000), 85-96.

United Nations High Commissioner for Refugees [UNHCR]. UNHCR Policy on Refugee Protection and Solutions in Urban Areas, September 2009. Retrieved from http://www.unhcr.org/refworld/docid/4ab8e7f72.html

UNHCR. (2011). The 1951 convention relating to the status of refugees and its 1967 protocol. Geneva, Switzerland.

UNHCR. (2015a). Global appeal 2015: Thailand. Retrieved from http://www.unhcr.org/5461e60b17.html

UNHCR. (2015b). Thailand. Retrieved from http://www.unhcr.org/pages/49e489646.html

UNHCR. (2016). Thailand factsheet: January 2016. Bangkok, Thailand.

UNHCR. (2017a). Asylum- seekers. Retrieved from http://www.unhcr.org/en-us/asylumseekers.html

UNHCR. (2017b). Urban refugees. Retrieved from http://www.unhcr.org/en-us/urbanrefugees.html

Universal Periodic Review. (2015). Kingdom of Thailand: Universal periodic review2nd Cycle. Kingdom of Thailand. Submitted 21 September 2015 on behalf of Asia Pacific Refugee Rights, Asylum Access, Human Rights Development Foundation, Jesuit Refugee Services, Migrant Working Group, and People's Empowerment Foundation.

Unterhitzenberger, J., Eberle-Sejari, R., Rassenhofer, M., Sukale, T., Rosener, R., \& Goldbeck, L. (2015). Trauma-focused cognitive behavioral therapy with unaccompanied refugee minors: A case series. BMC Psychiatry, 15, 260-273. doi: https://doi.org/10.1186/s12888-015-0645-0

Vervliet, M., Vanobbergen, B., Broekart, E., \& Derluyn, I. (2014). The aspirations of Afghan unaccompanied refugee minors before departure and at arrival in the host country. Childhood: A Global Journal of Child Research, 22(3), 330-345. doi: https://doi.org/10.1177/0907568214533976

Yanow, D. (2000). Conducting interpretive policy analysis. Thousand Oaks, CA: Sage Publications. doi: https://doi.org/10.4135/9781412983747

Author note: Address correspondence to: Aster S. Tecle, PhD, College of Social Work, University of Utah, 395 S 1500 East. Salt Lake City, UT 84112. E-mail:

aster.tecle@utah.edu 
Acknowledgements: We are very grateful for the contributions of individuals seeking refuge for their participation in this project. Their willingness to meet with the research team and their openness with sharing their stories and experiences has extended our understanding of their lived experiences and provide much needed information to community partners and organizations who serve and advocate for and with these communities. Additionally, we appreciate the time and participation of the many community partners and agencies located in Bangkok who provide support to these communities. Our special thanks to the staff and administration of Jesuit Refugee Service, Thailand for their vision and leadership in requesting this study and partnering at all stages of the work to develop a partnership focused on assisting communities in forced migration and improving the systems that serve these communities. 